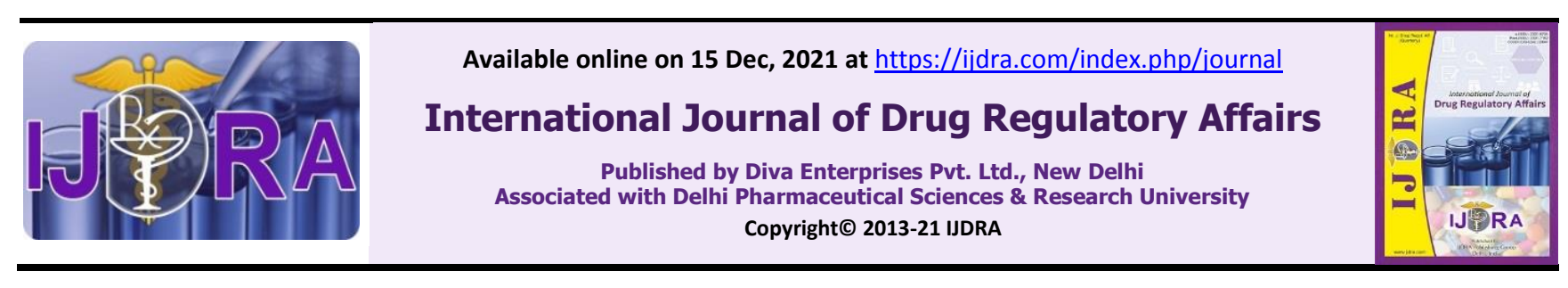

Review Article

Open $\odot$ Access

\title{
Preventing Prescription Drug Misuse: A Regulatory Perspective in the United States, Europe, and India
}

\author{
Dhruvi B Thakker*,a, Kalpana G Patel ${ }^{\text {b }}$ \\ ${ }^{a}$ M. Pharm Research Scholar, Department of Regulatory Affairs, Anand Pharmacy College, Near Town Hall, Anand, Gujarat 388001, \\ India \\ ${ }^{b}$ Professor and Vice Principal Department of Quality Assurance, Anand Pharmacy College, Near Town Hall, Anand, Gujarat 388001, \\ India
}

\begin{abstract}
Prescription medicines, such as analgesics, stimulants, steroids, anti-depressants, psychotropics, and certain antibiotics are commonly mishandled in a variety of ways, including overdosing, abuse, diversion, and drug trafficking. Because of the considerable risk to public health, they are subject to strict regulatory oversight. The drugs possess abuse potential at specific dose and hence prone to abuse therefore they are categorized as Controlled substances. Therefore, they are subject to constant vigilance over the pharmaceutical supply chain. The complete clinical data as well as post marketing surveillance study of such drugs are critical to be in place as per the regulatory requirements. The countries have kept up with the times by constantly updating the system with regulatory laws and strategies to prevent cases of misuse. The current review will give a quick summary of how prescription medications and prohibited substances are regulated in the United States, Europe, and India. It will also emphasize current trends in drug usage, as well as the issues that these countries face and the preventive policies implemented to manage and prevent drug misuse. It will also make recommendations for new regulatory initiatives to address the current drug- misuse-related concerns. As a result, a review of the regulatory system in various countries will present current challenges and new lessons for countries around the globe.
\end{abstract}

Keywords: Prescription drug, Controlled substances, Drug misuse, Drug overdose, Drug Abuse, Drug diversion, Drug trafficking

Article Info: Received 10 Nov. 2021; Review Completed 12 Dec. 2021; Accepted 15 Dec. 2021

Cite this article as:

Thakker DB, Patel KG. Preventing Prescription Drug Misuse: A Regulatory Perspective in the United States, Europe, and India. Int J Drug Reg Affairs [Internet]. 2021 Dec 15 [cited 2021 Dec 15]; 9(3):46-52. Available from:

http://ijdra.com/index.php/journal/article/view/502

DOI: $10.22270 / i j d r a . v 9 i 4.502$

*Corresponding author

\section{Introduction}

Pharmaceuticals are subject to regulation right from the development to post-marketing phase until it provides intended benefit to the patient. Drugs dispensed to the patients only after consent and prescription of a registered physician are called Prescription drugs. These drugs can become harmful to the health when used out of their specification. It could have a negative impact on public health, which is a major concern for the country.

Category of drugs that are highly misused includes sedatives, stimulants, opioids, and tranquilizers. The misuse can be in any of the ways that includes, overdosing, abusing, diversion, trafficking. Overdosing is when a patient takes a larger dose of the drug than that prescribed by the doctor to overcome intolerance of certain medical conditions. Abusing is when someone takes a substance for a non-medical reason in order to obtain euphoria. Its consequence may lead a person to get highly addicted to a drug which may badly impact his health. Diversion simply means illegally distributing a prescription to someone for illegal purpose. Trafficking is the illegal sale and distribution of Narcotics and Psychotropic agents over the supply chain.(1) Drugs or chemicals that may cause addiction and are subject to misuse as described above get categorized under controlled substances. Under stringent acts and regulatory agencies, these acts and laws control its manufacture, sale, distribution, and use throughout the country. Despite such laws, there has been rising evidence of prescription drug misuse in different parts of the world, demanding active monitoring of the drugs.

\section{Evidence on Drug Misuse}

Several research and review have been taken into consideration to get insights into trends in prescription drug misuse at various levels among healthcare and the public sector. Drug substances alone or in combination with other drugs and finished pharmaceuticals intended for therapeutic effects in the treatment of disease are 
subject to misuse or abuse by inappropriate dosage administration, non-medical use, off-label use, unauthorized or non-prescription access, and selfmedication.

An increase in opioid drug and Methamphetamine overdose got reported in the US amid Covid- 19.(2) Gabapentin drug approved for its antiepileptic and analgesic mechanism has been prescribed highly for an off-label purpose. Recent epidemiology studies and published case reports show that gabapentin misuse accounts for $1 \%$ internationally, used for recreational purposes and intentional self-harm. (3) The EU-wide systematic review gave in-depth on the abuse of prescription drugs used as Novel Psychoactive Substances. It included pregabalin, venlafaxine, olanzapine, and clenbuterol.(4) Shreds of evidence were found from a study in North India, showing misuse of topical steroids and clobetasol propionate. The driving factor was the prevailing misconceptions for a skin disease that drove the public to seek unauthorized access to prescription medicines. (5) Medication misuse prevailing among antibiotics resulted from inappropriate prescribing, non-script dispensing by the pharmacist, and poor knowledge among consumers. (6) Drug diversion evidence among HIV patients was found globally for analgesics, anti-retroviral, psychoactive drugs, sedatives, and stimulants since they are at high risk of infection and pain. (7) Indigenous production of heroin, psychotropic and prescription drug and their rising demand in international market has made Indian border vulnerable to drug trafficking. (8) Cocaine usage in North America and Europe is the greatest in the world. It is primarily transported by sea from Columbia. (9)

Misuse of drugs occurs at several phases of the regulatory process. The lack of knowledge about prescribing the right drug and dose among physicians lead to drug overdose or drug misuse in the case of antibiotics. (6) Administering a higher dosage of central nervous system agents caused withdrawal symptoms and addictive effects among patients. Doctors specializing in complementary medicine prescribing for allopathic drugs are not legal. (5) Pharmacists dispensing without the prescription of a registered physician and proper patient counseling should be subject to strict regulation. Consumers and patients unaware of medicinal side effects go for self-administration and also use the drug for recreational purposes may lead to adverse events. Unauthorized websites and e-pharmacy selling medicines are highly responsible for the illegal sale and distribution of controlled substances making drug trafficking a common crime. Since the beginning of time, prescription medications have been regulated. But the rising trends of its misuse ask for time-specific updating of its regulatory strategies. Pharmaceutical regulatory affairs never stop exercising its laws and regulation right after marketing authorization of drugs. The vigilance of drug safety over the supply chain and assuring its intended use for the patient is the responsibility of drug regulators post-marketing. The violation of drug laws leading to self and public harm is an offense subject to enforcement and punishments leading to a national setback. Hence, it is necessary to bring education about drug laws, correct use, and its adverse effects among professionals and patients, and adopt preventive strategies by drug regulators worldwide. The objective of the article is to draw special attention to the regulation of prescription drugs and controlled substances in the US, Europe, and India; to provide a review on the current trend of prescription drug misuse in different parts of the world; to spotlight the challenges, control, and preventive strategies for drug misuse in the current context.

\section{Regulation of Prescription Drugs and Controlled Substances}

Public health is protected by regulatory authorities at both the national and international levels. They implement laws to ensure that people have access to safe and effective medications. The current regulation provides a system for control and monitoring of prescription drug misuse. The objective is to regulate prescription drugs and controlled substances throughout the lifecycle and enforce strict actions on illegal drugs with abuse potential. The regulatory system also provides current data on drugs use and its consequences on misuse. It has a tracking system to get information and adopt effective measures to control drug trafficking nationwide. The regulatory strategy and efficiency to monitor, control, and prevent drug misuse varies in different countries based on government, technology, and the economy. Hence a review of the regulatory system in various countries will provide current challenges and new lessons to countries around the globe.

\section{Regulation in US (10)}

The Federal Food, Drug, and Cosmetics Act regulate prescription medications in the United States (FFDCA). Regulatory agencies enacting laws for prescription drugs and controlled substances for their safety, abuse control, illicit trafficking is as follows:

- Department of Health and Human Services' Food and Drug Administration (DHHS)

- Drug Enforcement Administration (DEA)

- Department of Justice (DoJ)

Some special laws and regulatory requirements that apply to the drug are as follows:

\section{Prescription drug}

Prescription Drug Marketing Act- This act came into being in 1987 to ensure the supply of safe and effective drugs in the market. The legislation prevents the sale of low-quality and counterfeit drugs throughout the distribution chain and improve safeguards for the public. The regulatory requirements and guidelines for manufacturers, wholesalers, and pharmacies are provided under Title 21 of Code of Federal Regulation Chapter I FDA, DHHS Subchapter C- Drugs: General.

\section{Controlled substances}

The Comprehensive Drug Misuse Prevention and Control Act (CDAPA) was enacted in 1970 to impose 
regulations on the pharmaceutical industry, including required security and record- keeping for certain medications with abuse potential.

Controlled Substance Act- It is a part of the CDAPC Act, comprised of laws to regulate the production and supply of addictive or habit-forming drugs like narcotics, steroids, and stimulants, and drug substances classified

Table 1. Classification of Scheduled Drugs in the US according to their medical indication and abuse potential into five schedules described in the Table 1. (11)

The regulatory requirements for manufacturers, distributors, and dispensers of Controlled Substances are under Title 21 of Code of Federal Regulation Chapter II DEA, Department of Justice.

\begin{tabular}{|c|c|c|}
\hline Schedule & Description & Examples \\
\hline Schedule I & No accepted medical use; High abuse potential & Heroin, Marijuana \\
\hline Schedule II & $\begin{array}{l}\text { Severe potential for psychological dependence; } \\
\text { High abuse potential }\end{array}$ & Cocaine, Methadone \\
\hline Schedule III & $\begin{array}{l}\text { Moderate to low potential for psychological } \\
\text { dependence }\end{array}$ & $\begin{array}{l}\text { Containing }<90 \mathrm{mg} \text { codeine, } \\
\text { anabolic steroids }\end{array}$ \\
\hline Schedule IV & $\begin{array}{l}\text { Low abuse potential and low risk of psychological } \\
\text { dependence }\end{array}$ & Xanax, Tramadol \\
\hline Schedule V & $\begin{array}{l}\text { Lowest abuse potential and limited quantities of } \\
\text { certain narcotics }\end{array}$ & $\begin{array}{l}\text { Containing }<200 \mathrm{mg} \text { codeine, } \\
\text { Lomotil }\end{array}$ \\
\hline
\end{tabular}

Prescription drugs cannot be dispensed without the oral or written prescription of the practitioner. In the US, the government authorizes registered medicinal practitioners to prescribe drugs and controlled substances after issuing unique Drug Enforcement Administration numbers (DEA numbers) and National Provider Identifier (NPI). These numbers ultimately aid in identifying and tracing the genuine prescription.

\section{Regulation in Europe (12)}

Europe has a centralized regulatory agency called European Medicine Agency which regulates certain medicinal products in its 27 member states and European Free Trade Area. Some rules are implemented at the national level by member countries. In Europe, provisions for Prescription-only medicines (POM) and controlled substance laws, legislated at the National level, except for drug precursor laws, are legislated at the EU level. The monitoring committees at the EU level provide an authentic database on the drug, its addiction status, and the health consequences. The reliable data on drug usage patterns and drug problems, along with factors leading to illicit use and some specific preventive measures, are also highlighted based on trending regulatory challenges. Regulatory agencies playing a

Table 2. Classification of Scheduled Drugs in Europe central role in monitoring and controlling drugs misuse are:

\section{- European Medicine Agency (EMA)}

- European Monitoring Centre for Drugs and Drug Addiction (EMCDDA)

The drug policies and laws governed in Europe apply to Drug precursors (primary chemicals), Scheduled substances (Annexure I), and Non-scheduled substances (not in Annex I) that are subject to misuse for non-legal purposes. In the EU, controlled substances are categorized based on their ease of potential to abuse, and are described in the Table 2.

- Regulation (EC) No111/2005, as amended by Regulation (EU) No1259/2013, establishing rules for monitoring drug precursor traffic between the EU and other nations

- Regulation (EC) No273/2004, as revised by Regulation (EU) No1258/2013, regulating trade surveillance among European countries

These legislations were set to achieve harmonized use of drugs and prevent drug diversion, abuse, and trafficking from and within the European administration (13)

\begin{tabular}{lll}
\multicolumn{1}{c}{$\begin{array}{c}\text { Category of } \\
\text { scheduled } \\
\text { Substances }\end{array}$} & \multicolumn{1}{c}{ Description } & \multicolumn{1}{c}{ Examples } \\
\hline Category 1 & Highly sensitive substance; subject to high illicit use & 1-phenyl-2-propanone, piperonal \\
\hline Category 2 & Less sensitive substances & Acetic anhydride; piperidine \\
\hline Category 3 & Bulk chemicals & Acetone, HCl \\
\hline \hline Category 4 & $\begin{array}{l}\text { Medicinal products that contain ephedrine or } \\
\text { pseudoephedrine }\end{array}$ & Barbital, ephedrine \\
\hline
\end{tabular}

\section{Regulation in India (14)}

The drug is listed under multiple schedules of The Drugs \& Cosmetics Act, 1940 and Rules 1945 in India, and is subject to regulatory oversight. The regulatory authorities that regulate the manufacture, import, distribution, and sale of prescription medicines and controlled substances with abusive potential, are stated below:

- Central Drugs Standard Control Organization (CDSCO) 
- Narcotics Control Bureau (NCB)

\section{- National Anti-Doping Agency (NADA)}

The legal laws and acts for the regulation of drugs are special for vigilance and controlling misuse of addictive and habit-forming drugs are:

The 1940 Drugs and Cosmetics Act (D \& C Act)- It regulates the manufacture, import, distribution, and supply of all scheduled drugs and cosmetics listed under this act.

The Narcotic Drugs and Psychotropic Substances

Table 3. Classification of Scheduled Drugs in India
Statute (NDPS) of 1985- An Indian parliamentary act that punishes and outlaws anyone who engages in the illicit use or misuse of narcotic drugs and psychotropic substances. (15)

The 1988 Act to Prevent Illicit Trafficking in Narcotic Drugs and Psychotropic Substances- An act implemented for complete enforcement of the NDPS Act to monitor and prevent illegal trafficking of controlled substances.

As per the D \& C Act, scheduled drugs are prescription drugs and controlled substances, classified as given in the Table 3. (14)

\begin{tabular}{|c|c|c|}
\hline Schedule & Description & Examples \\
\hline Schedule H (Rx drugs) & Prescription drugs & $\begin{array}{l}\begin{array}{l}\text { Antibiotics, } \\
\text { progestational }\end{array} \\
\text { hypertensives, }\end{array}$ \\
\hline Schedule X (NRx drugs) & $\begin{array}{l}\text { Narcotic and } \\
\text { Agents }\end{array}$ & $\begin{array}{l}\text { Narcotics Drug- Any drug, derivative, } \\
\text { or formulation containing coca, opium, } \\
\text { and/or cannabis, Psychotropic } \\
\text { Substances-Barbital, Diazepam, } \\
\text { Cyclidines }\end{array}$ \\
\hline
\end{tabular}

\section{Drug misuse as a regulatory challenge}

Drug misuse is the result of changing scenario, and the economy in the country may give rise to malpractices related to drugs and medicines. The lack of knowledge about the adverse consequences of drug misuse among the public is a vital regulatory challenge for Health authorities. Evidence of precarious living situations has led to people selling and distributing addictive drugs illegally as a means of generating revenue, which is a leading cause of drug trafficking. The imbalance in demand and supply of drugs has posed a challenge over the pharmaceutical supply chain amid the Covid-19 pandemic. It has led to the illegal sale of high- demand medicines into the Black Market. Some illicit drug trafficking channels have readily accepted corrupt practices by the involvement of some state officials that has been an obstacle to ineffective legislation of drug misuse. It has made access to these drugs easier for the rich, at high prices, in the same way depriving the middle class and poor violating the "Health for all" concept as proposed by WHO.

\section{US}

The Covid-19 outbreak has posed additional concerns for people with substance use disorder (SUD), making them more vulnerable to unauthorized drug-use patterns. Physicians' inability to differentiate patients seeking medicine in the context of pain or drug dependence leads to overuse. The use of buprenorphine and methadone as substitutes in opioid therapy might lead to dependency. Another big difficulty for drug regulators is polypharmacy and doctor shopping, which have been prevalent for a long time. $(16,17)$

\section{Europe}

The evolution of novel psychoactive substances and lack of a database on the abusive potential of certain drugs during the clinical study has generated a new route for drug overdose and drug abuse. The online global market and innovative commercialization strategies along emerging crypto markets have posed challenges on drug policy demanding its new regulation for online pharmacy supply. The lack of regulatory harmonization for controlled substances is another major challenge in the EU. In France, for example, over-the-counter medications are more expensive than prescription drugs. It discourages self-medication and increases reliance on medical advice. In Germany, on the other hand, the patient is encouraged to self-medicate. $(18,19)$

\section{India}

The quick emergence of e-pharmacy is the major challenge prevailing in India. Drug trafficking through Indian borders marks the lack of active monitoring of drug misuse in India. Since the easing of prescription opioid legislation, there has been an increase in opioid drug usage. The revision of the "essential narcotic drugs" list included painkillers like morphine, codeine, and hydrocodone are subject to drug abuse. The lack of regulation for post-marketing surveillance and database on Phase IV study is another cause of drug misuse in India. (20)

\section{Current strategies addressing drug misuse}

The international and country-wide regulatory agencies are trying their best to update laws that address prescription drug misuse and substance abuse. Drug monitoring post-market and tracing illegal drug trade are some of the actions undertaken by regulators. Though the efficiency of the drug surveillance system varies in terms of regulation and government of the country, stringent and harmonized regulation for prescription drugs is the key regulatory measure. 
The National Institute on Drug Abuse (NIDA) is a US federal research organization. Its objective is to look into drug use habits and the bad consequences associated with it. It also addresses essential questions about drug abuse, developing new strategies, treatment, and preventive approaches to drug addiction. (21) To prevent prescription medications from being misused, the US FDA has imposed strict controls. However, the state's prescription drug overdose death problem continues. Addressing this regulatory challenge under Public Health Law Program, the Centre for Disease Control and Prevention has created legal strategies as described below to overcome this challenge. (22)

- Laws on Prescription Drug Dosage and Time Limits

- Medical examinations are required

- Laws Concerning Doctor Shopping

- Requirements for tamper-proof prescription forms

- State-by-State Identification of Prescription Drugs

- Regulation of Pain Management Clinics

- State Laws in the Event of a Prescription Drug Overdose

EU has adopted a multidisciplinary approach to address drug violations. Rules on new psychoactive substances are updated to efficiently detect harmful substances in the market and act rapidly to ban them. The EMCDDA actively monitors drug phenomena and updates data on trends in drug abuse. The EU has enhanced its drug security system by increasing the detection of drug trafficking at checkpoints. It has also undertaken to curb illicit drug production and cultivation to reduce its supply. A step to educate people about adverse drug effects and improve access to standard treatment for people with substance use disorder will reduce drug demand. Detoxification and rehabilitation programs, opioid replacement therapy, and psychosocial techniques to address drug-related harm are all aspects of harm reduction interventions undertaken in the EU. $(23,24)$

India has adopted strategies to balance drug supply and demand and harm reduction-related to drugs. The Drug De-Addiction Program aided in accomplishing the

Table 4. Comparative overview of regulation for prescription drug and controlled substance in the US, Europe, India

\begin{tabular}{|c|c|c|c|}
\hline Parameter & US & European Union & India \\
\hline Regulatory Authorities & $\begin{array}{l}\text { US FDA; } \\
\text { DEA; } \\
\text { NIDA }\end{array}$ & $\begin{array}{l}\text { EMA; } \\
\text { EMCDDA }\end{array}$ & $\begin{array}{l}\text { CDSCO; } \\
\text { NCB }\end{array}$ \\
\hline Regulatory Laws & $\begin{array}{l}\text { Prescription Drug } \\
\text { Marketing Act; } \\
\text { Comprehensive Drug } \\
\text { Abuse Prevention and } \\
\text { Control Act; } \\
\text { Controlled Substance Act }\end{array}$ & $\begin{array}{lll}\text { Regulation } & \text { (EC) } & \text { No } \\
111 / 2005 ; & & \\
\text { Regulation } & \text { (EC) } & \text { No } \\
273 / 2004 & & \end{array}$ & $\begin{array}{l}\text { The Drugs \& Cosmetics Act); } \\
\text { Narcotic Drugs and } \\
\text { Psychotropic Substance Act; } \\
\text { Prevention of Illicit Trafficking } \\
\text { in Narcotic Drugs and } \\
\text { Psychotropic Substances Act }\end{array}$ \\
\hline $\begin{array}{l}\text { Drug classification } \\
\text { system }\end{array}$ & $\begin{array}{l}\text { Classification based on } \\
\text { the abusive potential of } \\
\text { drugs in Schedule I, II, } \\
\text { III, IV, V }\end{array}$ & $\begin{array}{l}\text { Classification based on } \\
\text { the risk of abuse in } \\
\text { Category } 1,2,3,4\end{array}$ & $\begin{array}{l}\text { Generalized classification } \\
\text { system; } \\
\text { Schedule H- Prescription drugs } \\
\text { Schedule X- Narcotics and } \\
\text { psychotropics agents }\end{array}$ \\
\hline
\end{tabular}

mission. The Ministry of Health and Welfare created health program aimed at treating and rehabilitating those who are addicted to drugs. Narcotics Control Bureau and Central Bureau of Investigation have constant vigilance on illegal drug use and illicit trade throughout the country. However, it has a long time to go to make it a nationwide regulatory system. $(20,25)$

\section{Future scope to prevent drug misuse}

For a long time, drug abuse has been prevalent. The as coordination among various authorities, will aid in the fight against prescription medication misuse. Doctors, pharmacists, and patients must carry out their duties honestly and without creating minor opportunities for drug misuse. The essential takeaways for doctors, pharmacists, and patients include appropriate prescribing practices, good dispensing methods, and the correct dosage and administration. To combat drug misuse, regulatory activities must be taken with vigor. Eprescriptions and oral prescriptions, which guarantee validity, are preferable to written prescriptions. Premarket studies do not always provide complete information about a drug's potential for abuse. As a result, prescription monitoring procedures and postmarket surveillance must be properly implemented to provide continuous vigilance against drug misuse. Preventing drug dependency in patients can be accomplished by limiting long-term prescriptions. Understanding patients' drug-related behavior patterns should be based on clinical follow-up and sociobehavioral intervention. There should be early warning mechanisms in place to track new pharmaceuticals as formulation is gaining traction, one that will keep the drug's medical indication while also preventing addiction to specific habit-forming medications. Globally harmonized regulation and the adoption of multinational policies will aid in the global fight against drug misuse.

8. Overview of Prescription Drug and Controlled Substance Regulatory scenario in the US, Europe and India international harmonization of drug regulations, as well they enter the market. A new method to abuse-deterrent 


\begin{tabular}{llll}
\hline $\begin{array}{l}\text { Preparedness and } \\
\text { Preventive approach }\end{array}$ & $\begin{array}{l}\text { Special laws for the } \\
\text { prevention of } \\
\text { prescription drug misuse }\end{array}$ & $\begin{array}{l}\text { Programs and } \\
\text { techniques for reducing } \\
\text { drug supply, demand, } \\
\text { and harm }\end{array}$ & $\begin{array}{l}\text { Drug Monitoring program and } \\
\text { strategies to reduce drug } \\
\text { supply, demand, and harm }\end{array}$ \\
\hline \hline $\begin{array}{l}\text { Post-market } \\
\text { surveillance }\end{array}$ & Mandatory & Mandatory & Mandatory \\
\hline
\end{tabular}

\section{Conclusion}

Prescription medication usage has been a regulatory concern for the country, according to the analysis. To combat drug-related harm caused by the drug usage patterns identified here, strict regulation and harmonization are critical. The comparative overview of prescription medication and controlled substance regulation provides a quick look at the US, EU, and India's present regulatory outlook, issues, and preventive actions. Regulations in the United States are stricter than in Europe and India, which strengthens the system. To combat drug misuse, the EU has developed active monitoring and surveillance systems. However, in terms of addressing drug problems, it lacks legal consistency across its member nations. In India, there is more widespread regulation of prescription pharmaceuticals and controlled substances, with no indication of the level of risk a drug may pose to a patient. Though there is a dearth of regulation to undertake a post-market analysis, the monitoring mechanism to trace drug trafficking is in existence. The post-marketing surveillance of a new drug on the market will be able to provide useful information on the drug's potential for abuse. It will give important information if there is a shortage of knowledge about the drug's abuse liability from the premarket study. Physicians should be able to identify if a patient is at risk for drug abuse based on their medical history before administering such medication. The effective tracking and record of data throughout supply chain will reduce its chances of being misused. In this study, the problems and preventive techniques are discussed in order to provide lessons on how to control and prevent prescription drug usage.

\section{Acknowledgements}

We would like to express our sincere gratitude to IJDRA Journal for publishing our article

Financial Disclosure statement: The author received no specific funding for this work.

\section{Conflict of Interest}

The authors declare that there is no conflict of interest regarding the publication of this article.

\section{References}

1. U.S. National Library of Medicine. medlineplus.gov [Internet]. NLM; 2021 [cited 2021 Nov 16]. Available from:

https://medlineplus.gov/prescriptiondrugmisuse.html.

2. Haley, Danielle F. and Saitz, Richard. The Opioid Epidemic During the COVID-19 Pandemic. JAMA; 2020.

3. Rachel V. Smith, Jennifer R. Havens, and Sharon L. Walsh. Gabapentin misuse, abuse, and diversion: A systematic review. HHS Public Access; 2016.

4. Fabrizio Schifano, Stefania Chiappini, John M. Corkery and Amira Guirguis. Abuse of Prescription Drugs in the Context of Novel Psychoactive Substances (NPS): A Systematic Review: brain sciences; 2018.

5. Molly Thomas, Celestine C Wong, Pam Anderson, Nathan Grills. Magnitude, characteristics and consequences of topical steroid misuse in rural North India: an observational study among dermatology outpatients: BMJ Open; 2020.

6. Porter G, Grills N. Medication misuse in India: a major public health issue in India. J Public Health (Oxf). 2016 Jun; 38(2):e150-7.

doi: 10.1093/pubmed/fdv072. Epub 2015 Jun 8. PMID: 26060236.

7. Chibi B, Torres NF, Sokhela ZP, Mashamba-Thompson TP. Prescription drug diversion among people living with HIV: a systematic scoping review. Public Health. 2019 Dec; $177: 26-43$.

doi: 10.1016/j.puhe.2019.07.017. Epub 2019 Sep 5. PMID: 31494360.

8. Pushpita, Das. Drug Trafficking in India: A Case for Border Security; May; 2012.

9. United Nations Office on Drugs and Crime.unodc.org. [Internet]. 2021[cited 2021 Nov 15]. Available from: https://www.unodc.org/unodc/drug-trafficking/index.html

10. U.S. Food \& Drug Administration. accessdata.fda.gov. [Internet]. FDA; 2020 Apr [cited 2021 Nov 18]. Available from:

https://www.accessdata.fda.gov/scripts/cdrh/cfdocs/cfcfr/ CFRSearch.cfm?CFRPart $=1305$

11. United States Drug Enforcement Administration. dea.gov. [Internet]. [cited 2021 Nov 12]. Available from: https://www.dea.gov/drug-information/csa

12. The European regulatory system for medicines. ema.europe.eu. [Internet].EMEA; 2016 [cited $2021 \mathrm{Nov}$ 11]. Available from:

https://www.ema.europa.eu/en/documents/leaflet/europea n-regulatory-system-medicines-european-medicinesagency-consistent-approach-medicines_en.pdf

13. European Monitoring Centre for Drugs and Drug Addiction. emcdda.europa.eu. [Internet]. [cited 2021 Nov 16]. Available from:

https://www.emcdda.europa.eu/publications/topicoverviews/classification-of-controlled-drugs/html_en

14. Rules, The Drugs and Cosmetics Act and. cdsco.gov.in. [Internet]. CDSCO; 2016 Dec [cited 2021 Nov 16]. Available from:

https://cdsco.gov.in/opencms/export/sites/CDSCO_WEB/ Pdfdocuments/acts_rules/2016DrugsandCosmeticsAct194 0Rules1945.pdf

15. THE NARCOTIC DRUGS AND PSYCHOTROPIC SUBSTANCES, ACT, 1985. legislative.gov.in. [Internet]. [cited 2021 Nov 16]. Available from: https://legislative.gov.in/sites/default/files/A1985-61.pdf

16. Ornell F, Moura HF, Scherer JN, Pechansky F, Kessler FHP, von Diemen L. The COVID-19 pandemic and its impact on substance use: Implications for prevention and treatment. Psychiatry Res. 2020 Jul;289:113096. doi: 10.1016/j.psychres.2020.113096. Epub 2020 May 13. PMID: 33242814.

17. Stefania Chiappini, Amira Guirguis, John Martin Corkery \& Fabrizio Schifano. et al. Misuse of prescription and over-the-counter drugs to obtain illicit highs: how 
pharmacists can prevent abuse. The Pharmaceutical Journal; 2020 Dec.

18. Neicun J, Steenhuizen M, van Kessel R, Yang JC, Negri A, Czabanowska K, Corazza O, Roman-Urrestarazu A. Mapping novel psychoactive substances policy in the EU: The case of Portugal, the Netherlands, Czech Republic, Poland, the United Kingdom and Sweden. PLoS One. 2019 Jun 26;14(6):e0218011.

doi: 10.1371/journal.pone.0218011. PMID: 31242225; PMCID: PMC6594604.

19. T., Casati A. Sedefov R. Pfeiffer-Gerschel. Misuse of Medicines in the European Union: A Systematic Review of the Literature. European Addiction Research; 2012.

20. Ghosh, Ajit Avasthi and Abhishek et al. Drug misuse in India: Where do we stand \& where to go from here? Indian Journal of medical Research; 2019 Jun.

21. National Institute on Drug Abuse. [Internet]. drugabuse.gov [cited 2021 Nov 16]. Available from: https://www.drugabuse.gov.

22. Center for Disease Control and Prevention cdc.gov[Internet]. 2018 Jun [cited 2021 Nov 16]. Available from: https://www.cdc.gov/phlp/publications/topic/prescription. html.

23. Eur-Lex: Access to European Union Law. eurlex.europa.eu. [Internet].EU; 2021 Jan 13 [cited 2021 Nov 10]. Available from: https://eur-lex.europa.eu/legalcontent/EN/ALL/?uri=CELEX\%3A32004R0273

24. European Commission Drugs policy. ec.europa.eu. [Internet].EC; 2021 [cited 2021 Nov 15]. Available from: https://ec.europa.eu/home- affairs/policies/internalsecurity/organised-crime-and-human-trafficking/drugpolicy_en

25. Narcotics Control Bureau India. narcoticsindia.nic.in. [Internet]. 2021 [cited 2021 Nov 16]. Available from: https://narcoticsindia.nic.in 